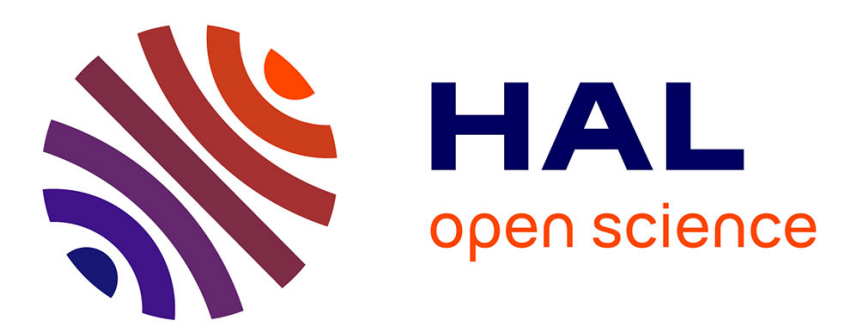

\title{
Economic model of albumin infusion in septic shock: The EMAISS study
}

Bertrand R. Guidet, Idir Ghout, Jacques Ropers, Philipe Aegerter

\section{To cite this version:}

Bertrand R. Guidet, Idir Ghout, Jacques Ropers, Philipe Aegerter. Economic model of albumin infusion in septic shock: The EMAISS study. Acta Anaesthesiologica Scandinavica, 2020, 64 (6), pp.781-788. 10.1111/aas.13559 . hal-02927535

\section{HAL Id: hal-02927535 \\ https://hal.science/hal-02927535}

Submitted on 24 Feb 2021

HAL is a multi-disciplinary open access archive for the deposit and dissemination of scientific research documents, whether they are published or not. The documents may come from teaching and research institutions in France or abroad, or from public or private research centers.
L'archive ouverte pluridisciplinaire HAL, est destinée au dépôt et à la diffusion de documents scientifiques de niveau recherche, publiés ou non, émanant des établissements d'enseignement et de recherche français ou étrangers, des laboratoires publics ou privés.

\section{(c)(1)}

Distributed under a Creative Commons Attribution| 4.0 International License 


\section{Economic Model of Albumin Infusion in Septic Shock: the EMAISS study}

Bertrand Guidet $\mathrm{MD}^{1}$, Idir Ghout $\mathrm{MSc}^{2}$, Jacques Ropers MD $\mathrm{PhD}^{3}$, and Philippe Aegerter $\mathrm{MD} \mathrm{PhD}{ }^{4}$.

1- Sorbonne Université, INSERM, Institut Pierre Louis d'Epidémiologie et de Santé Publique, AP-HP, Hôpital Saint-Antoine, service de réanimation, F75012, Paris, France. bertrand.guidet@aphp.fr

2- URC Paris ouest, AP-HP, Hôpital Ambroise Paré, Boulogne-Billancourt, France idir.gi@gmail.com

3- Dpt Santé Publique - UMR 1168 UVSQ INSERM. jacques.ropers@aphp.fr

4- GIRCI IdF - UFR Médecine Paris-Ile-de-France-Ouest Université Versailles StQuentin. 9, avenue Charles de Gaulle. 92100 Boulogne, France. philippe.aegerter@uvsq.fr

\section{Corresponding Author:}

Prof. Bertrand Guidet

Medical ICU, Hôpital saint Antoine, 184 rue du Faubourg saint Antoine, 75012 Paris, France Tel: +33149282318 / Fax: +33149282145

e-mail: bertrand.guidet@aphp.fr

Word count : abstract : 245 ; manuscript : 3588 ; references 41 ;

Tables : 3 ; figures 3 , SEM : 13 


\section{Abstract}

BACKGROUND: The cost-effectiveness of albumin-based fluid support in patients with septic shock is currently unknown.

METHODS: In a simulation study, we compared standard medical practice and systematic $20 \%$ albumin infusion. The study population consisted of patients with septic shock admitted to one of the 28 ICUs belonging to the Cub-Réa regional database between 1st January 2014 and 31st December 2016. Cost estimates were based on French diagnosis related groups and fixed daily prices. Estimation of mortality reduction relied on ALBIOS trial data documenting a Risk Ratio of 0.87 in a nonpreplanned subgroup of patients with septic shock. Life expectancy was estimated with follow up data of 184 patients with septic shock admitted in year 2000 in the same ICUs. Several sensitivity analyses were performed including a one-way Deterministic Sensitivity Analysis (DSA) and a Probabilistic multivariate Sensitivity Analysis (PSA).

RESULTS: 6406 patients were included. In the base-case scenario, the mean live years gained with albumin was 0.49 . The mean extra cost of using albumin was $€ 480$ per year. The cost per year gained was $€ 974$. Sensitivity analyses confirmed the robustness of the results. The probability of albumin being cost effective was $95 \%$ and $97 \%$ for a threshold fixed at $€ 20,000$ and $€ 30,000$ per life year saved, respectively.

CONCLUSION: On the basis of the risk reduction observed in the septic shock subgroup analysis of the ALBIOS dataset, the application of the ALBIOS trial results to Cub-Réa data may suggest that albumin infusion is likely cost-effective in septic shock.

Keywords: Cost-effectiveness; albumin; septic shock; economic model 
Sepsis is a major healthcare problem with high mortality rates and carrying an important economic burden (1-4). Septic shock is defined as a specific subset of sepsis in which underlying circulatory, cellular, and metabolic abnormalities are associated with a greater risk of mortality (5), and it is diagnosed by a vasopressor requirement to maintain a mean arterial pressure $\geq 65 \mathrm{~mm} \mathrm{Hg}$ and serum lactate levels $>2 \mathrm{mmol} / \mathrm{L}$, in the absence of hypovolemia. Resuscitation with intravascular fluids is one of the key interventions in septic patients and has the aim to correct symptomatic hypovolemia and restore vital organ perfusion. Although fluid resuscitation is commonly carried out, some important questions are still a matter of debate (6).

According to the current Surviving Sepsis Campaign Guidelines, crystalloids are recommended as the fluid of choice for initial resuscitation and subsequent intravascular volume replacement in patients with sepsis and septic shock. When these patients require substantial amounts of crystalloids, the use of albumin in addition to crystalloids is suggested for initial resuscitation and subsequent intravascular volume replacement (7).

Albumin is widely used in clinical practice and it is known for some physiological properties other than the maintenance of oncotic pressure, such as antioxidant effects and positive effects on vessel wall integrity (8). Albumin interacts with the glycocalyx and reduces vascular permeability (9), thus enhancing microcirculatory function in critically ill patients (10). Albumin is able to restore endothelial response to acetylcholine (11)

In the SAFE (Saline versus Albumin Fluid Evaluation) trial, albumin was shown to be as safe and effective as $0.9 \%$ saline in a pool of Intensive Care Unit (ICU) patients requiring fluid administration, and a trend towards a mortality reduction was 
specifically observed in patients with severe sepsis (12). On the contrary, the use of artificial colloids such as hydroxyethyl starches (HES) has been banned in patients with sepsis, due to safety concerns, including renal function deterioration and mortality (13, 14). Another large trial, the ALBIOS (ALBumin Italian Outcome Sepsis) one, including patients with septic shock as well as patients with severe sepsis, addressed the efficacy of albumin added to crystalloids in improving survival compared to crystalloids alone; no overall mortality benefit was shown in patients with sepsis, but lower 90-day mortality was observed with albumin in the subgroup of patients with septic shock (Relative risk -RR-0.87; 95\% CI 0.77-0.99) (15). However, another French trial did not documented any mortality reduction of Human Albumin in patients with septic shock (16). Some meta-analyses have also stated the benefit of albumin in terms of survival in patients with sepsis $(17,18)$ and specifically with septic shock (19), while others have concluded to a lack of effect of albumin on mortality 20,21).

An obstacle for the use of albumin in patients with septic shock might be its price, as it can be perceived as an expensive option if only the cost of the product is considered (22). However, albumin has been described as more cost-effective than crystalloids and HES when total medical costs and complications are considered (23). In 2007, the COASST study, comprising a population of patients with severe sepsis or septic shock included in the Cub-Réa database, and considering the $4.6 \%$ reduction in mortality observed in the SAFE trial, also concluded that albumin is cost-effective in those patients (24).

Considering the results of ALBIOS trial (15), the aim of the EMAISS (Economic Model

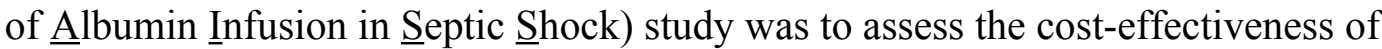
albumin in patients with septic shock, under standard medical practice in French ICUs.. 


\section{Methods}

\section{Patients and treatment}

The data used in this cost-effectiveness study were collected from the Cub-Réa database $(25,26)$. Cub-Réa has been gathering data from ICUs located in Paris and its surrounding area, since 1996. The Cub-Réa database is compliant with the French law, and has been approved by the French data protection authority (Commission Nationale de l'Informatique et des Libertés, CNIL). Participating ICUs prospectively collect standardized information from admission to death or hospital discharge: diagnosis (coded using the $10^{\text {th }}$ revision of the International Statistical Classification of Diseases and Related Health Problems -ICD10- and the Diagnosis-Related Group -DRG-), severity of illness, patients' characteristics and medical procedures. All data are recorded in each ICU with standardized database software. Quality-assurance controls are applied to ensure consistency between the diagnoses and procedures. The data are transmitted anonymously to the coordinating center in a once a year basis.

Patients admitted with septic shock (ICD10 code "R572") to one of the 28 participating ICUs from $1^{\text {st }}$ January 2014 to $31^{\text {st }}$ December 2016 were included. All patients received either epinephrine or norepinephrine. Patients with ascites and likely to receive albumin were excluded. Only the first stay was included in the analysis for those patients admitted two or more times due to septic shock.

Long-term survival was determined from a group of 184 patients admitted to the ICU for septic shock between 1998 and 2000, who fulfilled the Cub-Réa inclusion criteria (27), and whose 10-year vital status was obtained from the French Epidemiological Centre on causes of deaths (CepiDc) (28). Their characteristics were compared to those included in our study using either Chi-square test or Student t-test, as appropriate. 


\section{Model}

A decision tree model was developed to estimate ICU costs and health outcomes when using either albumin and crystalloids or crystalloids alone in patients with septic shock, from ICU admission and over lifetime horizon. Different analyses were made for those patients being discharged alive from hospital or dying within hospital (Figure S1). Albumin administration was assumed to last for a maximum duration of 7 days.

The data obtained from Cub-Réa database for this analysis were age, sex, ICU length of stay (ICU-LOS) for patients who died in hospital, ICU-LOS for patients discharged alive, hospital LOS for patient who died at hospital, hospital LOS for patient discharged alive, mortality rate with crystalloids and cost of hospital stay per day. The reduction of mortality with albumin compared to crystalloids alone in patients with septic shock was taken from the ALBIOS trial (15).

\section{Estimation of costs and life expectancy}

For this analysis, the perspective of the French National Health System (Caisse Nationale d'Assurance Maladie) was adopted. Medical direct costs incurred during the ICU stay and related to the treatment strategies were included in the analysis, considering both tariffs (29) and prices as costs. The total ICU cost was calculated by multiplying ICU-LOS by the sum of septic shock costs (DRG costs when managed in public hospitals) per day plus an additional daily fixed price for ICU stay, paid by the French National Health System. The cost of albumin was derived from the administered quantity value in the ALBIOS trial (15) and the ICU-LOS of patients included in this study and the price of vial in France. Because all costs were incurred during the first months (during the ICU stay), no discounting method was used. 
The DEALE (Declining Exponential Approximation of Life Expectancy) method for calculating life expectancy was used to estimate the average life expectancy (30). In order to estimate life-expectancy according to age and sex, the estimated annual septicshock-specific mortality rate and the Mortality Tables by Social Category and Diploma, published in 2016, were used (31). The excess mortality rates were derived from the data of 184 patients admitted to ICU from 1998 to 2000, who survived from their septic shock and for whom the 10 year vital status after hospital discharge was available, and the French's life mortality tables estimated during the same period

\section{Base-case analysis}

The Incremental Cost-Effectiveness Ratio (ICER), i.e. the difference in cost per lifeyear gained for albumin vs crystalloids alone, was estimated using the mean values of the parameters presented in Table 1 as inputs of our model.

\section{Sensitivity analysis}

In order to appraise the uncertainty of our estimations, several sensitivity analyses were performed including a one-way Deterministic Sensitivity Analysis (DSA) and a Probabilistic multivariate Sensitivity Analysis (PSA). In DSA, the inputs of the model were changed one by one using extreme values for each parameter and the ICER was recalculated. In PSA analysis, except for the price of albumin and the additional daily price for ICU stay, which are fixed, the value of the inputs variables were simulated from their respective distribution. 2,000 simulations were done and the results in terms of incremental cost and life-years gained were presented as cost-effectiveness plane and ICERs were presented as acceptability curve.

Furthermore, to account for the uncertainty of other variables when conducting the DSA, both approaches were combined (DSA and PSA). For each deterministic variation done on one variable, PSA was conducted simultaneously on all other variables of the 
model, and the results were summarized as curves of the probability of costeffectiveness of albumin when willingness-to-pay threshold is fixed at 10,000, 20,000 or $€ 30,000$, according to the deterministic variations of each variable.

The robustness of the method used to estimate the life expectancy of patients discharged alive was assessed by performing a PSA using a Weibull model, which was fit on the Cub-Réa-2000 database and adjusted on age and sex. Subsequently, the estimated parameters (shape, scale and covariates parameters) were used to derive the survival curve according to the simulated patients based on Cub-Réa-2016 database. Mean survival was obtained by calculating the area under the extrapolated survival curves $(\mathrm{R}$ Core Team software, version 3.4.4, 2018; Foundation for Statistical Computing, Vienna, Austria).

\section{Results}

During the 3-year study period, a total of 86,152 ICU stays and 8,504 patients with septic shock ( $11 \%$ of the entire cohort) were recorded in the Cub-REA database. Patients with septic shock related to infected ascites and second or later stays after a first ICU stay were excluded leaving 6406 cases that fulfilled the inclusion criteria (Figure 1). Mean age of the population included was $66.3 \pm 15.3$ years and $37.9 \%$ were female (Table 1). Mean simplified acute physiology score (SAPS II) was $61.1 \pm 22.2$. Charlson comorbidity index was 0 in $39.2 \%$; 1 in $13.7 \%$; 2 in $23.2 \%$ and $>3$ in $23.9 \%$ (Table S1). Organ supports were: vasoactive drugs 100\% (as part of definition of septic shock), mechanical ventilation 80.5\%; renal replacement therapy (RRT) 17.2\%. Mean ICU-LOS for patients dying at the hospital and discharged alive was $12.27 \pm 16.85$ and $13.15 \pm 16.63$ days, respectively. Mean hospital-LOS for the same groups of patients was $17.54 \pm 24.4$ and $29.75 \pm 28.12$ days, respectively, and in-hospital mortality was $46.3 \%$. 
Survival rate at 10 years from hospital discharge estimated from the data of the 19982000 cohort was 32\% (95 CI: 26; 40) (Figure S2). Differences between the patients admitted during the two periods (2014-2016 and 1998-2000) were found in terms of mean age, SAPS II score, presence of comorbidities and percentage of patients requiring mechanical ventilation, as described in Table S1.

The relative risk ratio of mortality reported in the ALBIOS trial (0.87) was assumed, leading to a mean increase of 0.49 years in survival with albumin added to crystalloids compared to crystalloids alone.

The use of albumin was calculated to have an incremental cost of $€ 480$, compared to crystalloids. Consequently, the cost per life year gained with albumin was estimated to $€ 974$ (Table 2).

The scatterplot of ICER performed for 2,000 simulations is presented in Figure S3. Depending on the willingness-to-pay threshold set at $€ 20,000$ or $€ 30,000$ per life year saved, the probability of albumin being cost effective was $95 \%$ or $97 \%$, respectively, as shown in the acceptability curve (Figure 2).

As cost-effectiveness can be sensitive to different factors, a one way sensitivity analysis according to several factors, such as age of patients or length of hospital or ICU stays, is presented in Table 3. The results of DSA combined with PSA are presented in Figure 3 and Figures S4 for age, S5 for sex and S6, S7, S8, S9 for the impact of LOS and survival status. The probability of albumin being cost-effective seemed to be especially sensitive to the risk ratio of mortality (albumin/crystalloids). The analyses also show that the ICER with albumin plus crystalloids compared to crystalloids was sensitive to the variation of ICU-LOS ratio (albumin/crystalloids) (S10). Other factors have a moderate impact on probability that albumin is cost-effective, especially when $€ 10,000$ 
is considered willingness-to-pay threshold, are the annual septic shock-specific mortality (S11), number of Albumin vials infused (S12) and cost of hospital stay (S13).

\section{Discussion}

Cost of healthcare interventions is certainly an issue today (32) and it will need to be even more considered in the future (33). In the case of patients with sepsis, its incidence and expenses are extremely high, as it is the mortality rate after discharge (34).

Consequently, the use of efficient and cost-effective interventions should be of priority in septic patients. In the case of albumin on a per unit basis, it could be considered an expensive fluid used in resuscitation of patients with sepsis, although clinical outcomes and their costs need to be considered in order to choose the most appropriate treatment.

The EMAISS study is based on recent data, and a large number of patients admitted to 28 ICUs during 2014-2016 were included. The study was restricted to septic shock patients, and a very favorable cost-effectiveness acceptability curve was estimated either with DEALE or Weibull methods. Life expectancy was estimated using real data with more than 10 years follow-up of patients admitted in the same ICUs for septic shock. This study offers new pharmacoeconomic data on the use of albumin in patients with septic shock, confirming that albumin is cost-effective compared to crystalloids. In the base-case scenario, a mean of 0.49 life years were estimated to be gained in patients treated with albumin plus crystalloids versus patients receiving crystalloids alone, and the incremental cost was $€ 480$. Considering this data, the cost per life-year gained with albumin resulted to be $€ 974$. Sensitivity analyses confirmed the robustness of the model and also that the ICER was favorable to albumin in most scenarios.

A previous study also reported an increase in life-years in patients receiving resuscitation with albumin compared to crystalloids: 0.21 life-years gained were 
observed when using albumin in patients with severe sepsis (with an incremental cost of \$270), while 0.85 life-years were lost when using HES, (23). The higher benefit reported with albumin in our study might be related to inclusion of patients with septic shock while in Farrugia's study, it was patient with severe sepsis. Although with a different perspective, the ICER was estimated at $\$ 1,285$, which is very close to our findings. The same study stated that the treatment with albumin dominated HES in patients with severe sepsis, that it was more cost-effective than crystalloids, and reported a total cost per life-year of $\$ 9,253$, being the cheapest of the three treatments (albumin, HES and crystalloids). The much higher cost reported in that study compared to ours might be related to several factors: lower life expectancy, higher cost of albumin, consideration of the cost of bleeding and renal replacement therapy.

In the COASST study, which also analyzed the cost-effectiveness of albumin in patients with sepsis registered in the Cub-Réa database (24), the number of lives saved with albumin was 512 out of 11,137 patients included. The average life expectancy of the patients receiving albumin discharged alive was estimated to be 9.78 years (deduced from underlying disease and immediate severity, and only of patients discharged alive from hospital), instead of 4.92 years (calculated from solid data of long-term follow-up of patients admitted in the Cub-Réa ICUs ) reported in the EMAISS study, and the costs per life saved and per year of life saved observed were $€ 6,037$ and $€ 617$, respectively. These figures are actually comparable, since around 10 years of life expectancy estimated at the discharge alive from hospital (estimated on one half of the population) is equivalent to the life expectancy of around 5 years at ICU admission, because there is $50 \%$ deaths in ICU. Since the costs are estimated for the entire cohort, the same is true for life expectancy. 
Some other differences between both studies existed in the characteristics of the populations included: patients with severe sepsis in the COASST study and with septic shock in the EMAISS study, younger (mean age of 64.0 vs 66.3 years), and in-hospital mortality rate without albumin of $53.7 \%$ vs $46.4 \%$ (despite patients being more severely ill in the EMAISS, evidenced by a mean SAPS II score of 61.1 vs 55 at the COASST study), respectively. The mean ICU and hospital-LOS resulted to be shorter in the EMAISS study and the respective inclusion periods were also different (2014-2016 vs 1998-2002).

In the EMAISS study the computation of mortality reduction $(6.3 \%)$ relied on the ALBIOS trial results, while in the COASST study data came from the SAFE trial (4.6\%); in the base-case scenario, $220 \mathrm{~g}$ of albumin were infused in the ALBIOS trial, while $88 \mathrm{~g}$ of albumin were infused in the SAFE trial. The cost considered for $20 \mathrm{~g}$ of albumin was $€ 36.7$ in the EMAISS study, and $€ 61.80$ in the COASST study,

The EMAISS and Albios population are different: The patients are younger and more severely ill in CUB-REA cohort. The hospital LOS was close to 28 days in CUB-REA and mortality was higher than the mortality reported at D28 in Albios. These differences are consistent with inclusion of only $2 / 3$ of patients with septic shock in Albios trial while $100 \%$ of CUB-REA patients had septic shock.

The main limitation of the EMAISS study is the estimation of mortality reduction in the albumin arm. The basis for the current analysis is the sub-group results of the ALBIOS trial suggesting a large mortality reduction with the use of $20 \%$ albumin in patients with septic shock. This is problematic as this subgroup was not pre-planned - the analysis may have been data-driven, which increases the risk of chance findings. Also the allocation was not stratified for shock increasing the risk of baseline imbalance. Furthermore, the definition of shock did not fulfill sepsis 3 criteria. There are numerous 
precedents for non-pre-specified analysis which could lead to conclusions of false benefit arising from multiple testing (35). However, the benefit in mortality risk obtained with albumin in the ALBIOS trial is consistent with the results reported in one meta-analysis including the three most recent trials including patients with sepsis or septic shock (pooled relative risk in all the three trials of 0.92 [95\% CI, 0.84 to $1.00(\mathrm{p}=$ 0.046]) (18). We combined the results of a RCT and data extracted from a medicoadministrative data base. The quality of the data is probably different in the two bases since the data of RCT are monitored. However, the strength of this approach is to have real life data originating from 28 different ICUs. The $11 \%$ incidence of septic shock and 46\% in-hospital mortality are consistent with septic shock epidemiology. Another limitation is the inclusion of only French ICUs and the results should be duplicated in other countries.

We did not include the EARSS trial (16) in the analysis because although some results were made public that did not confirm the results of Albios, the study was never published and could not be subjected to rigorous scientific appraisal.

It should be emphasized that, in the ALBIOS trial, albumin administration was not restricted to the first hours but also included albumin supplementation for 28 days after enrollment. These data, together with the lack of effects in patients enrolled with early sepsis, suggest that there are beneficial effects associated with albumin use in relation to its ancillary functions, rather than only to its primary oncotic properties (36).

Another concern is the assumption that Cub-REA patients did not receive Albumin. We don't have the type and volume of fluid received by patients in CUB-REA. However the French recommendations are not in favor of colloids and albumin either for vascular filling (37) or for prevention of acute renal failure (38) As a consequence, the percentage of patients in French ICUs receiving colloids in the Fluid TRIPS survey was 
$15 \%$ (39) with only $50 \%$ of colloids being Albumin. So we might speculate that very few patients received Albumin in the CUB-REA cohort considering that patients with infected ascites were excluded.

This is an important piece of information since the cost of albumin is often used to justify rationing albumin infusion $(40,41)$. The ALBIOS data do not indicate how much albumin patients with septic shock received. For all patients, the median volume of albumin was $1,100 \mathrm{~mL}$. Considering the cost of $25 \%$ albumin in the United States, it was estimated a median cost of $\$ 902$ per case of septic shock (in the first 7 days) (41), which is close to the incremental cost in our study. In this last paper, the additional cost per life saved was estimated to be $\$ 14,384$, whereas our cost of $€ 974$ was estimated per life-year gained. Applying the survivors' life expectancy at the Cub-Réa ICU in our model (around 10 years) to their ratio would result in an ICER close to ours (around $\$ 14,000$ for 10 years). Albumin has also been shown to reduce the incidence of some complications or morbidity compared to crystalloids (9) and these differences could also have an important impact on direct healthcare costs.

A potential adverse effect of albumin on renal function was not considered (23), as no clear signal of harm has been reported in previous studies, except for huge amount of albumin with very high resulting oncotic pressure (9), which is not the case of the patients included in the EMAISS study.

\section{Conclusion}

On the basis of the risk reduction observed in the septic shock subgroup analysis of the ALBIOS dataset, albumin-based fluid support may be cost-effective for patients admitted to the ICU with septic shock. 


\section{List of abbreviations}

CepiDc: French Epidemiological Centre on causes of deaths

DEALE: Declining Exponential Approximation of Life Expectancy

DRG: Diagnosis-Related Group

DSA: Deterministic Sensitivity Analysis

HES: hydroxyethyl starches

ICD10: International Statistical Classification of Diseases and Related Health Problems

ICER: Incremental Cost-Effectiveness Ratio

ICU: Intensive Care Unit

ICU-LOS: Intensive Care Unit length of stay

PSA: Probabilistic multivariate Sensitivity Analysis

RRT: Renal Replacement Therapy

SAPS II: Simplified Acute Physiology Score II

\section{Declarations}

Ethics approval and consent to participate: The Cub-Réa database is compliant with the French law, and has been approved by the French data protection authority (Commission Nationale de l'Informatique et des Libertés, CNIL). 
Consent for publication: Not applicable

Availability of data and material: The dataset supporting the conclusions of this article is available upon request to the president of CUB-REA network (bertrand.guidet@aphp.fr)

Competing interests: B Guidet received honorarium for lecture, by Grifols.

Funding: A grant from Grifols was obtained to conduct the study. The sponsor had no interference on the study (design, analysis, publication).

\section{Authors' contributions:}

BG initiated, conducted and finalized the Work.

IG, JR and PA conducted the economic analysis.

PA is the administrator of CUB-REA data base and conducted the long-term follow-up study.

BG, IG, JR and PA contribute to the draft of the manuscript.

All authors read and approved the final manuscript."

Acknowledgements: Jordi Bozzo, Francisco Mota and Jemina Moretó (Grifols) are acknowledged for medical writing assistance and preparation of the manuscript. 


\section{Legend of figures:}

Figure 1. Flow chart of patient selection

Figure 2. Cost-effectiveness acceptability curve

Figure 3. Probability that albumin being cost-effective according to the RR of mortality. 


\section{References}

1. Angus DC, Linde-Zwirble WT, Lidicker J, Clermont G, Carcillo J, Pinsky MR. Epidemiology of severe sepsis in the United States: analysis of incidence, outcome, and associated costs of care. Crit Care Med. 2001;29(7):1303-10.

2. Martin GS, Mannino DM, Eaton S, Moss M. The epidemiology of sepsis in the United States from 1979 through 2000. N Engl J Med. 2003;348(16):1546-54.

3. Quenot JP, Binquet C, Kara F, Martinet O, Ganster F, Navellou JC, et al. The epidemiology of septic shock in French intensive care units: the prospective multicenter cohort EPISS study. Critical care (London, England). 2013;17(2):R65.

4. Zhou J, Qian C, Zhao M, Yu X, Kang Y, Ma X, et al. Epidemiology and outcome of severe sepsis and septic shock in intensive care units in mainland China. PloS one. 2014;9(9):e107181.

5. Shankar-Hari M, Phillips GS, Levy ML, Seymour CW, Liu VX, Deutschman CS, et al. Developing a New Definition and Assessing New Clinical Criteria for Septic Shock: For the Third International Consensus Definitions for Sepsis and Septic Shock (Sepsis3). Jama. 2016;315(8):775-87.

6. Perner A, Hjortrup PB, Pettila V. Focus on fluid therapy. Intensive care medicine. 2017;43(12):1907-9.

7. Rhodes A, Evans LE, Alhazzani W, Levy MM, Antonelli M, Ferrer R, et al. Surviving Sepsis Campaign: International Guidelines for Management of Sepsis and Septic Shock: 2016. Critical care medicine. 2017;45(3):486-552.

8. Ferrer R, Mateu X, Maseda E, Yebenes JC, Aldecoa C, De Haro C, et al. Non-oncotic properties of albumin. A multidisciplinary vision about the implications for critically ill patients. Expert review of clinical pharmacology. 2018;11(2):125-37.

9. Vincent JL, Russell JA, Jacob M, Martin G, Guidet B, Wernerman J, et al. Albumin administration in the acutely ill: what is new and where next? Critical care (London, England). 2014;18(4):231.

10. Moret E, Jacob MW, Ranucci M, Schramko AA. Albumin-Beyond Fluid Replacement in Cardiopulmonary Bypass Surgery: Why, How, and When? Semin Cardiothorac Vasc Anesth. 2014;18(3):252-9.

11. Hariri G, Joffre J, Deryckere S, Bigé N, Dumas G, Baudel JL, Maury E, Guidet B, Ait-Oufella H. Albumin infusion improves endothelial function in septic shock patients. A pilot study. Intensive Care Med 2018, 44(5):669-671 
12. Finfer S, Bellomo R, Boyce N, French J, Myburgh J, Norton R. A comparison of albumin and saline for fluid resuscitation in the intensive care unit. $\mathrm{N}$ Engl $\mathrm{J}$ Med. 2004;350(22):2247-56.

13. Myburgh JA, Finfer S, Bellomo R, Billot L, Cass A, Gattas D, et al. Hydroxyethyl starch or saline for fluid resuscitation in intensive care. N Engl J Med.

2012;367(20):1901-11.

14. Perner A, Haase N, Guttormsen AB, Tenhunen J, Klemenzson G, Aneman A, et al. Hydroxyethyl starch 130/0.42 versus Ringer's acetate in severe sepsis. N Engl J Med. 2012;367(2):124-34.

15. Caironi P, Tognoni G, Masson S, Fumagalli R, Pesenti A, Romero M, et al. Albumin replacement in patients with severe sepsis or septic shock. N Engl J Med. 2014;370(15):1412-21.

16. Charpentier J, Mira JP, Group ES. Efficacy and tolerance of hyperoncotic albumin administration in septic shock patients: the EARSS study. Intensive Care Med 2011;37(suppl 1):S115.

17. Delaney AP, Dan A, McCaffrey J, Finfer S. The role of albumin as a resuscitation fluid for patients with sepsis: a systematic review and meta-analysis. Crit Care Med. 2011; 39(2):386-91.

18. Wiedermann CJ, Joannidis M. Albumin replacement in severe sepsis or septic shock. N Engl J Med. 2014;371(1):83.

19. Xu JY, Chen QH, Xie JF, Pan C, Liu SQ, Huang LW, et al. Comparison of the effects of albumin and crystalloid on mortality in adult patients with severe sepsis and septic shock: a meta-analysis of randomized clinical trials. Critical care (London, England). 2014;18(6):702.

20. Jiang L, Jiang S, Zhang M, Zheng Z, Ma Y. Albumin versus other fluids for fluid resuscitation in patients with sepsis: a meta-analysis. PloS one. 2014;9(12):e114666.

21. Patel A, Laffan MA, Waheed U, Brett SJ. Randomised trials of human albumin for adults with sepsis: systematic review and meta-analysis with trial sequential analysis of all-cause mortality. Bmj. 2014;349:g4561.

22. Vincent JL, Gottin L. Type of fluid in severe sepsis and septic shock. Minerva anestesiologica. 2011;77(12):1190-6.

23. Farrugia A, Bansal M, Balboni S, Kimber MC, Martin GS, Cassar J. Choice of Fluids in Severe Septic Patients - A Cost-effectiveness Analysis Informed by Recent Clinical Trials. Reviews on recent clinical trials. 2014;9(1):21-30. 
24. Guidet B, Mosqueda GJ, Priol G, Aegerter P. The COASST study: costeffectiveness of albumin in severe sepsis and septic shock. J Crit Care. 2007;22(3):197203.

25. Aegerter P, Auvert B, Buonamico G, Sznajder M, Beauchet A, Guidet B, et al. [Organization and quality control of a clinical database on intensive care medicine in central and suburban Paris]. Revue d'epidemiologie et de sante publique.

1998;46(3):226-37.

26. Sznajder M, Leleu G, Buonamico G, Auvert B, Aegerter P, Merliere Y, et al. Estimation of direct cost and resource allocation in intensive care: correlation with Omega system. Intensive care medicine. 1998;24(6):582-9.

27. Martel $\mathrm{P}$, Guidet $\mathrm{B}$, Aegerter $\mathrm{P}$. Évaluation de l'impact à long terme de la réanimation. Revue d'épidemiologie et de sante publique. 2011;59(S1);s33

\section{8. http://www.cepidc.inserm.fr}

29. https://www.atih.sante.fr/

30. Beck JR, Kassirer JP, Pauker SG. A convenient approximation of life expectancy (the "DEALE"). I. Validation of the method. Am J Med. 1982;73(6):883-8.

\section{1. https://www.insee.fr/fr/statistiques/1893092.}

32. Guidet B, Beale R. Should cost considerations be included in medical decisions? Yes. Intensive care medicine. 2015;41(10):1838-40.

33. Guidet B, van der Voort PHJ, Csomos A. Intensive care in 2050: healthcare expenditure. Intensive care medicine. 2017;43(8):1141-3.

34. Quartin AA, Schein RM, Kett DH, Peduzzi PN. Magnitude and duration of the effect of sepsis on survival. Department of Veterans Affairs Systemic Sepsis Cooperative Studies Group. JAMA. 1997;277(13):1058-63.

35. Wang R, Lagakos SW, Ware JH, Hunter DJ, Drazen JM. Statistics in medicine-reporting of subgroup analyses in clinical trials. N Engl J Med. 2007;357(21):2189-94.

36. Caironi P. POINT: Should Intravenous Albumin Be Used for Volume Resuscitation in Severe Sepsis/Septic Shock? Yes. Chest. 2016;149(6):1365-7.

37. Pottecher T, Calvat S, Dupont H, Durand-Gasselin J, Gerbeaux P; SFAR/SRLF workgroup. Haemodynamic management of severe sepsis: recommendations of the French Intensive Care Societies (SFAR/SRLF) Consensus Conference, 13 October 2005, Paris, France. Crit Care. 2006;10:311 
38. Brochard L, Abroug F, Brenner M, Broccard AF, Danner RL, Ferrer M, Laghi F, Magder S, Papazian L, Pelosi P, Polderman KH; ATS/ERS/ESICM/SCCM/SRLF Ad Hoc Committee on Acute Renal Failure. An Official ATS/ERS/ESICM/SCCM/SRLF Statement: Prevention and Management of Acute Renal Failure in the ICU Patient: an international consensus conference in intensive care medicine; Am J Respir Crit Care Med. 2010;181:1128-55).

39. Hammond NE, Taylor C, Finfer S, et al. Fluid-TRIPS and Fluidos Investigators; George Institute for Global Health, The ANZICS Clinical Trials Group, BRICNet, and the REVA research Network. Patterns of intravenous fluid resuscitation use in adult intensive care patients between 2007 and 2014: An international cross-sectional study. PLoS One. 2017;12(5):e0176292.

40. Vincent JL. Fluid management: the pharmacoeconomic dimension. Critical care (London, England). 2000;4 Suppl 2:S33-5.

41. Coz Yataco AO, Flannery AH, Simpson SQ. COUNTERPOINT: Should Intravenous Albumin Be Used for Volume Resuscitation in Severe Sepsis/Septic Shock? No. Chest. 2016;149(6):1368-70. 
Table 1. Model parameters

\begin{tabular}{|c|c|c|c|}
\hline Parameters & Value & Distributions & Sources \\
\hline Age. years & $66.3 \pm 15.32$ & Normal & $\begin{array}{l}\text { CubRea- } \\
2016\end{array}$ \\
\hline Female, $\mathrm{n}(\%)$ & $2429(37.92)$ & Beta & $\begin{array}{l}\text { CubRea- } \\
2016\end{array}$ \\
\hline $\begin{array}{l}\text { ICU length of stay for patient who died at } \\
\text { hospital, days }\end{array}$ & $12.27 \pm 16.85$ & Log-normal & $\begin{array}{l}\text { CubRea- } \\
2016\end{array}$ \\
\hline $\begin{array}{l}\text { ICU length of stay for patient discharged alive, } \\
\text { days }\end{array}$ & $13.15 \pm 16.63$ & Log-normal & $\begin{array}{l}\text { CubRea- } \\
2016\end{array}$ \\
\hline $\begin{array}{l}\text { Hospital LOS for patient who died at hospital, } \\
\text { days }\end{array}$ & $17.54 \pm 24.4$ & Log-normal & $\begin{array}{l}\text { CubRea- } \\
2016\end{array}$ \\
\hline Hospital LOS for patient discharged alive, days & $29.75 \pm 28.12$ & Log-normal & $\begin{array}{l}\text { CubRea- } \\
2016\end{array}$ \\
\hline ICU length of stay ratio (albumin/crystalloids) & $1(0.8,1.2)$ & $\begin{array}{l}\text { Continuous } \\
\text { uniform }\end{array}$ & Hypothesis \\
\hline Hospital mortality under crystalloids, n (\%) & $2974(46.43)$ & Beta & $\begin{array}{l}\text { CubRea- } \\
2016\end{array}$ \\
\hline RR of mortality in the albumin group* & 0.87 & Normal of $\ln (\mathrm{RR})$ & Albios \\
\hline Annual septic-shock-specific mortality, $\%$ & $7.12(4,10)$ & Beta-PERT & $\begin{array}{l}\text { CubRea- } \\
2000\end{array}$ \\
\hline Vial of $20 \%$ albumin for a week, $n$ & $11(5,20)$ & $\begin{array}{l}\text { Continuous } \\
\text { uniform }\end{array}$ & Albios \\
\hline Vial albumin cost, euros & 36.7 & & \\
\hline Cost of hospital stay per day, euros & $\begin{array}{l}642.88 \pm 610.2 \\
7\end{array}$ & Log-normal & $\begin{array}{l}\text { CubRea- } \\
2016\end{array}$ \\
\hline Additional cost due to ICU stay per day, euros & 804.07 & & ATIH \\
\hline
\end{tabular}

Data are mean $\pm \mathrm{SD}$, mean (minimum, maximum) or $\mathrm{n}(\%)$. ICU: Intensive Care Unit. LOS: length Of Stay. RR: Risk Ratio. ATIH: Agence technique de l'information sur l'hospitalisation.

Parameters of a beta distribution are derived from the $\mathrm{n}$ and the (\%). Thus $g=n$ and $h=n+(100-(\%)) /(\%)$.

Parameters of log-normal distribution are: $\exp \left(\mu+\sigma^{2} / 2\right)$ and $\left(\exp \left(\sigma^{2}\right)-1\right) * \exp \left(2 \mu+\sigma^{2}\right)$.

* The standard deviation of $\log (\mathrm{RR})$ was 0.064 .

$\uparrow$ The minimum and the maximum values are hypotheses. 
Table 2. Base-Case Analysis Results

\begin{tabular}{lccc}
\hline- & Albumin & Crystalloids & Incremental \\
\hline Mean life (years) & 4.9159 & 4.4231 & 0.4929 \\
Mean cost $(€)$ & 18916 & 18436 & 480 \\
Cost per year gained with albumin $(€)$ & & & 974 \\
\hline
\end{tabular}




\begin{tabular}{lccc}
\hline & $\begin{array}{c}\text { Base- } \\
\text { case }\end{array}$ & $\begin{array}{c}\text { Sensitivity } \\
\text { analysis }\end{array}$ & ICER \\
\hline & & base case & 974 \\
Age, years & 66.3 & $40 ; 80$ & $754 ; 1427$ \\
Female (\%) & 37.92 & $30 ; 50$ & $981 ; 965$ \\
ICU length of stay for patient who died at hospital, & 12.27 & $8 ; 20$ & $1731 ;-395$ \\
days & & & \\
ICU length of stay for patient discharged alive, days & 13.15 & $8 ; 20$ & $63 ; 2190$ \\
Hospital LOS for patient who died at hospital, days & 17.54 & $10 ; 25$ & $973 ; 977$ \\
Hospital LOS for patient discharged alive, days & 29.75 & $20 ; 40$ & $978 ; 971$ \\
ICU length of stay ratio (albumin/crystalloids) & 1 & $0.8 ; 1.2$ & $-6588 ;$ \\
& & & 8422 \\
Hospital mortality under crystalloids, \% & 46.43 & $35 ; 55$ & $1241 ; 847$ \\
RR of mortality in the albumin group & 0.87 & $0.77 ; 0.99$ & $619 ; 10818$ \\
Annual septic-shock-specific mortality,\% & 7.12 & $4.37 ; 11.59$ & $757 ; 1327$ \\
Vial of $20 \%$ albumin per week & 11 & $5 ; 20$ & $528 ; 1644$ \\
Vial albumin cost, euros & 36.7 & $30 ; 50$ & $824 ; 1271$ \\
Cost of hospital stay per day, euros & 642.88 & $450 ; 850$ & $954 ; 997$ \\
Additional cost due to ICU stay per day, euros & 804.07 & $804.07 ; 804.07$ & $974 ; 974$ \\
\hline
\end{tabular}

